\title{
Experimental study on the thermal performance of straight and oblique finned, polymer heat sinks
}

\author{
K. Timbs ${ }^{1}$, M. Khatamifar ${ }^{1}$, W. Lin $^{1}$ and E. Antunes ${ }^{1}$ \\ ${ }^{1}$ College of Science \& Engineering \\ James Cook University, Townsville, QLD 4811, Australia
}

\begin{abstract}
Heat sink can effectively dissipate heat in a range of thermal applications for improved performance and reliability. Thermally conductive polymer composites show great promise in solving the overheating issue in electronic devices. This experimental study investigates the thermal performance and the flow characteristics of straight and oblique finned heat sinks made of thermally conductive polymer composites under forced convection conditions over $7.45 \times 10^{4} \leq R e \leq 3.60 \times 10^{5}$, where $R e$ is the Reynolds number. The heat sinks used were $3 \mathrm{D}$ printed using Ice9 Flex (carbon filled polymer, from TCPoly), copper filled filament (polylactic acid with $80 \%$ copper particles) and bronze filled filament (polylactic acid with $80 \%$ bronze particles), respectively. Oblique fins were found to effectively reduce the thermal resistance of heat sinks, increase the convective heat transfer and the inner-fin velocity which results in lower pressure drop, in comparison to straight finned heat sinks. The carbon-filled polymer (Ice9 Flex) was shown to have much superior thermal dissipation characteristics compared to metal filled filaments.
\end{abstract}

\section{Keywords}

Thermally conductive polymer; heat sink; forced convection

\section{Introduction}

In the continual development of industrial devices aiming at the reduction in size and enhanced performance, heat dissipation has been a major issue. The reliability, lifetime, and performance of electronic devices are directly affected by the quality of electronic devices thermal management. It is reported that $55 \%$ of the environmental induced failures of electronic systems was due to overheating and the cost is $\$ 163$ million/year [1]. Previous studies have showed that a $1^{\circ} \mathrm{C}$ rise in the temperature can decrease the reliability of an electronic device by $4 \%$ and the failure rate may double by a $10 \sim 20^{\circ} \mathrm{C}$ increase [3]. Hence, with temperature effects being the major cause of electronic devices failure, the importance of developing cooling systems that improve component reliability and performance is rapidly increasing.

Heat sinks are prevailing heat dissipation devices and can be manufactured in a range of shapes and materials and exposed to different fluids. Heat sinks have an extensive range of applications including transport and automotive, lighting, electronic systems, and industrial facilities. Traditionally, heat sinks have been manufactured through the extrusion of metals, such as aluminium and copper, due to their high thermal conductivity. However, the thermal management of portable electronic devices creates new challenges and new, innovative materials with exceptional characteristics for thermal applications have emerged $[8,2,6,5]$.

The addition of different fillers to polymer matrices can enhance properties such as thermal conductivity. Thermal conductive polymer composite are significantly less dense and costeffective, and have the capability to provide comparable thermal performance, making them to have the potential to replace conventional heat sink materials as an emerging material for thermal management purposes $[9,11,4]$. The use of thermally conductive polymer composite which is $3 \mathrm{D}$ printable and injection mouldable provides significant liberties for the design and manufacturing of complex geometries [13].

Recent developments in 3D printing technology have led to applying this technology in many fields. One of the widely used 3D printing methods is fused deposition modeling (FDM) due to low-cost printers and a variety of inexpensive filaments. 3D printing provides great potential in the thermal management as it provides opportunities for the low-cost production of complex geometries $[12,10,14,7]$.

In this work, the thermal performance of straight and oblique finned heat sinks is studied experimentally. Heat sinks were 3D printed using three commercial thermal conductive filaments (Ice9 Flex, Copper filled filament, and bronze filled filament). The printed heat sinks were tested in a wind tunnel under a range of Reynolds numbers to examine important parameters including thermal resistance, temperature distribution, and pressure drop.

\section{Experiments}

\section{Materials}

In this work, two commercial metal based filaments (copper and bronze filled) were obtained from colorFabb B.V. and one carbon-based filament (Ice9 Flex) supplied by TCPoly, Inc. were used to 3D print heat sinks. The important properties of the materials used are presented in Table 1.

\begin{tabular}{lll}
\hline Material & Properties & Value \\
\hline Copper filled filament & matrix & polylactic Acid \\
& filler & copper \\
& density & $4000 \mathrm{~kg} / \mathrm{m}^{3}$ \\
& specific heat capacity & $668 \mathrm{~J} / \mathrm{kg} \cdot \mathrm{K}$ \\
& thermal conductivity & $0.7 \mathrm{~W} / \mathrm{m} \cdot \mathrm{K}$ \\
\hline Bronze filled filament & matrix & polylactic Acid \\
& filler & bronze \\
& density & $3900 \mathrm{~kg} / \mathrm{m}^{3}$ \\
& specific heat capacity & $708 \mathrm{~J} / \mathrm{kg} \cdot K$ \\
& thermal conductivity & $0.5 \mathrm{~W} / \mathrm{m} \cdot \mathrm{K}$ \\
\hline Ice9 Flex & matrix & polyurethane \\
& filler & proprietary filler \\
& density & $1550 \mathrm{~kg} / \mathrm{m}^{3}$ \\
& specific heat capacity & $1300 \mathrm{~J} / \mathrm{kg} \cdot \mathrm{K}$ \\
& thermal conductivity & $5 \mathrm{~W} / \mathrm{m} \cdot \mathrm{K}$ \\
\hline
\end{tabular}

Table 1. Important material properties

\section{Experimental setup}

Figure 1 schematically illustrates the experimental setup which comprises of the wind tunnel, the test section, and the data acquisition devices. The wind tunnel is an Armfield C1510 wind tunnel (an open-looped suction-type wind tunnel) 
equipped with a flow straightener at the inlet. In addition, several manometers are included to measure the pressure at various locations, which were used to determine both the fluid velocity and the pressure drop. The transparent test section of the wind tunnel (77 $\mathrm{mm}$ wide, $150 \mathrm{~mm}$ high, and $1100 \mathrm{~mm}$ long) was modified to place the heat sink package and a heater $(3.75 \mathrm{~W})$ attached to an MP-3084 laboratory power supply. To measure the temperature of the heat sink during experiments, a Testo 885 thermal imaging camera was used and the Testo IRSoft software, the compatible software for the infrared camera, was used for post-processing and reading the temperature at key points.

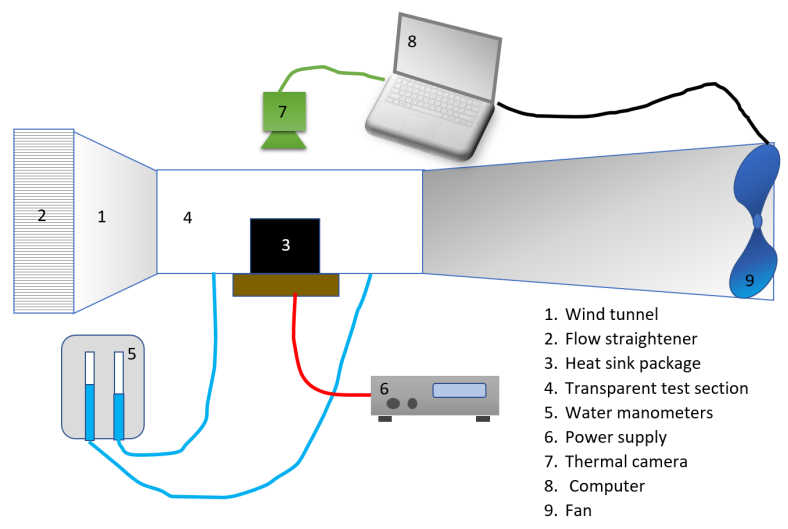

Figure 1. Experimental setup.

The heat sink package is also illustrated in fig. 2. This package includes low thermal conductive materials (a $20 \mathrm{~mm}$ thick polystyrene $(0.033 \mathrm{~W} / \mathrm{m} \cdot \mathrm{K})$ and a $10 \mathrm{~mm}$ thick wood layers) to minimize heat loss, bolts and nuts to increase contact pressure, and a $1 \mathrm{~mm}$ thick plate of copper to minimize thermal fluctuation during the experiment. Thermal paste was applied between the copper plate, the heat sink, and the heater to decrease thermal contact resistance.

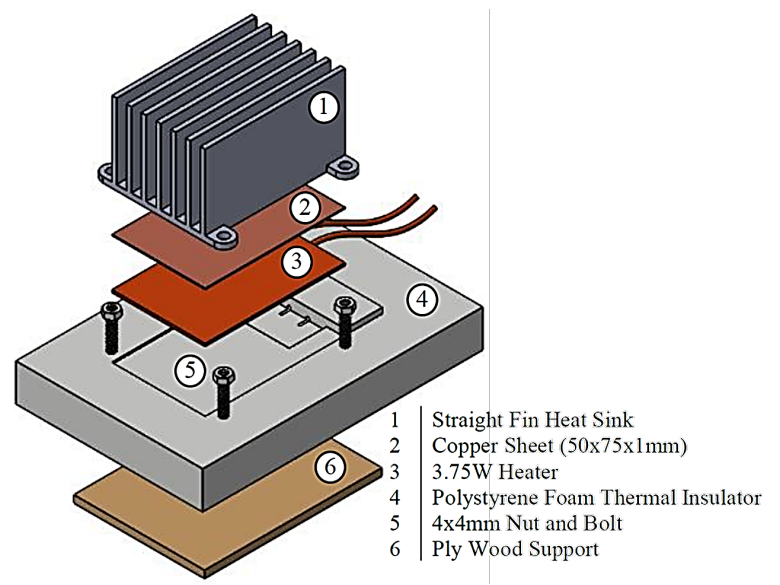

Figure 2. Heat sink package.

To ensure that the heat sinks with different geometries can be directly compared for their thermal performance and flow dynamics characteristics, the heat sinks have equal volume, base area $(75 \mathrm{~mm} \times 50 \mathrm{~mm})$ and thickness $(5 \mathrm{~mm})$, number of fins $(7$ fins), fin height $(40 \mathrm{~mm})$ and spacing at the base $(5.4 \mathrm{~mm})$. The detail dimensions of the designed heat sinks and the 3D printed heat sinks are presented in Figs. 3 and 4.

The experimental methodology was designed to test the thermal performance of a range of heat sink models under forced convection. During the experiments, the heat sink model was

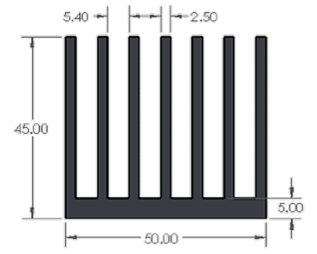

(a)

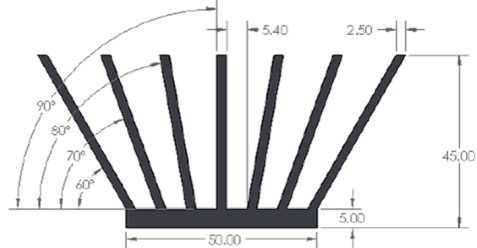

(b)
Figure 3. Detail dimensions of the heat sinks with (a) straight fins and (b) oblique fins.

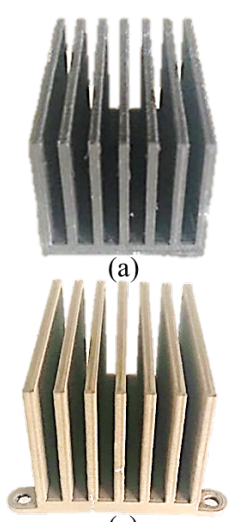

(c)

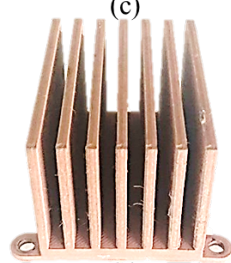

(e)

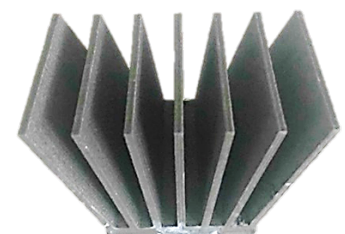

(b)

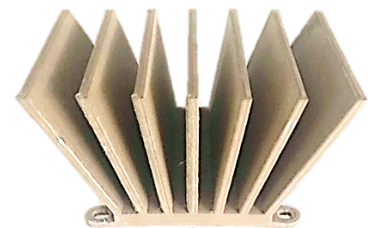

(d)

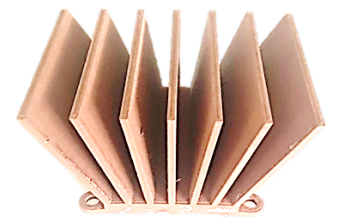

(f)
Figure 4. Printed straight finned and oblique finned heat sinks made of Ice9 Flex (a)-(b), bronze filled filament (c)-(d) and copper filled filament (e)-(f).

attached to the silicone heating pad and copper sheet before being placed inside the wind tunnel and its bases was heated with the heater. The wind tunnel software was used to control the speed of the fan. Each heat sink was tested under 6 different fluid velocities, ranging from $4.5 \sim 22 \mathrm{~m} / \mathrm{s}$. The thermal camera was positioned to capture thermal images. By positioning the camera perpendicular to the fluid flow, the side view of the heat sink fins was captured. An isometric image was then taken to capture the front, side and top views of the fins. The thermal data captured was then used to calculate the thermal resistance defined as,

$$
R_{t h}=\frac{T_{b}-T_{\infty}}{Q}
$$

where $T_{b}$ is the average base temperature, $T_{\infty}$ is the ambient air temperature, and $Q$ is the heat flux through the base of the heat sink, respectively.

Furthermore, to identify the movement of the fluid as it traveled through the heat sink, flow visualisation methods were utilised. This involved using a smoke generator machine to produce several streams of white smoke which were then positioned inside the wind tunnel via a rake which was dispersed across the heat sink. The final phase of the experimental testing was to measure the pressure drop across the heat sink using inclined water manometers. 
Scanning Electron Microscopy (SEM) and Energy Dispersive X-ray spectroscopy (EDS) were performed on a SU500 Scanning Electron Microscope to characterize the selected filaments. These methods were used to characterize the particle morphology and size distribution, the dispersion of particles within the filament, and to determine the chemical composition of the filament. The samples of bronze filled, copper filled and Ice9 Flex filaments were prepared by applying a thin layer of carbon coating prior to imaging. Each sample was viewed at a range of magnification levels with the use of Back-scattered electron (BSE) imaging to distinguish between materials of different atomic weights. This provided details of the particle size, geometry, and distribution within the base filament. The final process using the EDS provided the chemical composition of selected points on the surface of the filament.

\section{Results and discussion}

The SEM and EDS results of the filaments used are presented in Fig. 5. From the SEM results, it was found that the bronze and copper additives are spherical particles, ranging over approximately $1 \sim 40 \mu \mathrm{m}$.
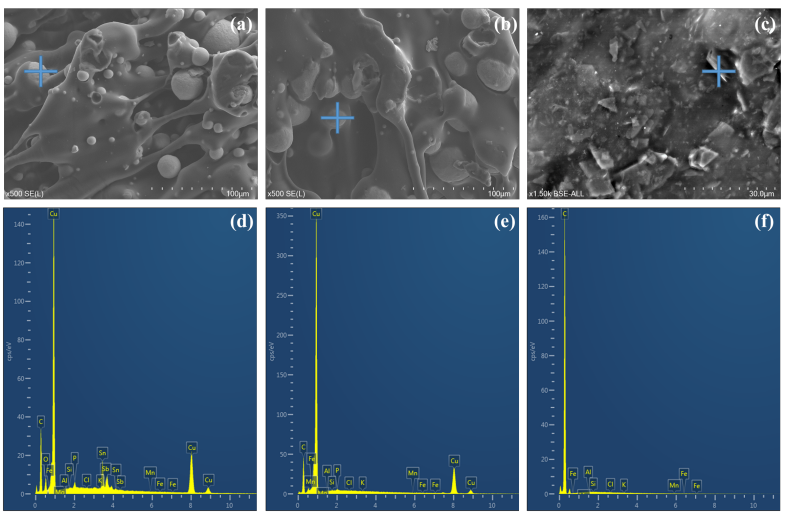

Figure 5. SEM and EDS results of the used filaments.

The results presented in Fig. 5(d) demonstrate that the chemical composition of bronze filled filament is mainly composed of copper $(\mathrm{Cu})$, with the addition of approximately $12 w t \%$ tin $(\mathrm{Sn})$ whilst the copper filled filament has copper as the major metal element, with the addition of small surface impurities.

Figure 6 presents the experimentally obtained thermal resistance of heat sinks with different geometries and materials over the Reynolds number range of $7.45 \times 10^{4} \leq R e \leq 3.60 \times 10^{5}$, where $R e$ is the Reynolds number, defined as,

$$
R e=\frac{v_{d} D_{h d}}{v}
$$

where $v_{d}$ is the ducted velocity, $D_{h d}$ the hydraulic diameter of the test section and $v$ the kinematic viscosity of air.

From the figure 6 , it is noted that the influence of $R e$ on the thermal resistance of the metal filled filaments is significantly larger than that of the carbon-filled filaments (Ice9 Flex filament) essentially over the whole range of $R e$ studied. In particular, the oblique finned heat sink with Ice8 Flex filament has a substantially lower thermal resistance than any of the other heat sinks tested. This is clearly a direct result of the combined improvement to the thermal performance provided by oblique fins and high thermally conductive material. Nevertheless, it is also observed that whilst the Ice9 Flex filament heat sinks outperforms the metal-filled ones for the majority of Re studied, once the flow reaches $R e=3.60 \times 10^{5}$, the metal-filled oblique finned heat sinks begin to outperform the Ice9 Flex filled straight finned heat sink. It is postulated that the difference in thermal resistance between metal-filled and Ice9 Flex filled heat sinks will further reduce with the increase of $R e$ but this is beyond the scope of the present study.

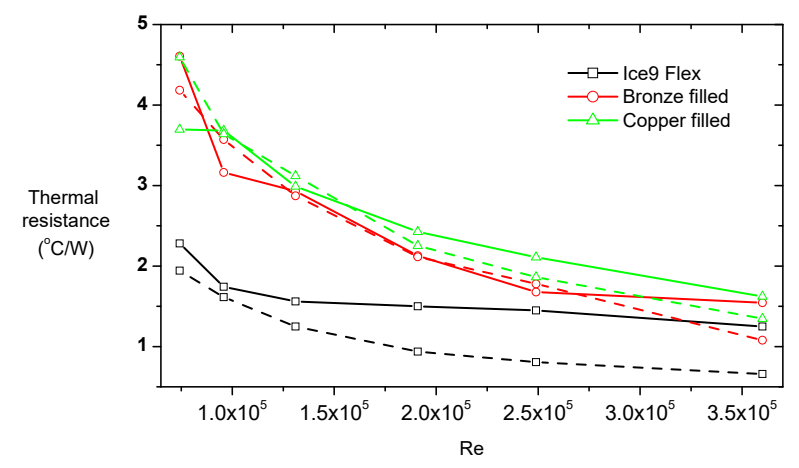

Figure 6. The experimentally obtained thermal resistance for the straight finned (solid line) and oblique finned (dashed line) heat sinks plotted against $R e$.

Figure 7 displays the relationship between the pressure drop and $R e$ for the straight finned and oblique finned heat sinks. It is seen that for all types of heat sinks tested, the pressure drop across the heat sinks increases monotonically and significantly with the increase of $R e$. This is because as air velocity increases, it suffers more frictional losses as flows through inter-fin spaces. However, the pressure drop across the oblique finned heat sink is in general smaller than that across the straight finned heat sink over the $R e$ range studied. This is due to larger inter-fin spaces which increase flow penetration into the heat sink (less flow bypass) in comparison to the straight finned heat sink.

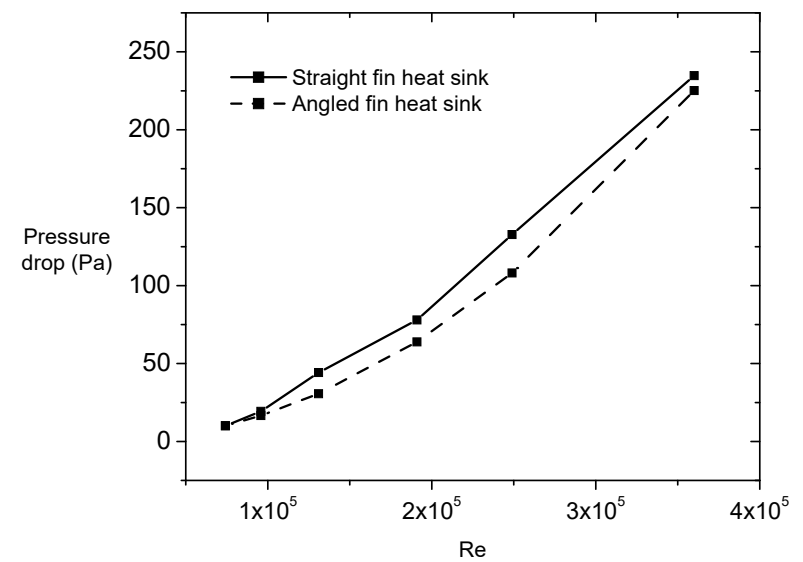

Figure 7. Pressure drop plotted against $R e$ for straight finned and oblique finned heat sinks.

To analyse the fluid flow path through the various heat sinks, the smoke visualisation technique was employed. Figure 8 illustrates a visualization of the movement of the fluid through the fins of the case of $R e=7.45 \times 10^{4}$ for the straight and oblique finned heat sinks. Analysing the images presented in Fig. 8(a)(b) for the fluid flow passing through the straight finned heat sink, highlights its high flow resistance identified in figure 7. From these images, it can be observed that the straight fins are subject to premature egress of the fluid flow from the inter-fin field. Following the streamline indicated by a red arrow shown in the figure which enters the fin field, it can be observed to exit the top of the heat sink, rather than pass across the face of the fins. The observed leak of the airflow out of the heat sink has an 
adverse effect on the heat transfer which also can be seen in figure 6 . This premature egress is due to the boundary layer formation in the fin channels along the sides of the fins which creates a high-pressure area at the trailing edge region. This layer narrows the remaining fin channel and blankets the fin thereby insulating it from the cooler airflow, retards efficient heat transfer, and contributes to its premature flow egress. The oblique finned design demonstrates much superior flow characterises through fins when compared to the straight finned design. As depicted in Fig. 8(c)-(d), there is relatively no premature flow egress for this design. Due to increase in inter-fin spacing which resulted in the lower flow resistance, the smoke streamlines show that flow remains in the heat sink. This flow behaviour improves the thermal performance of the heat sink.
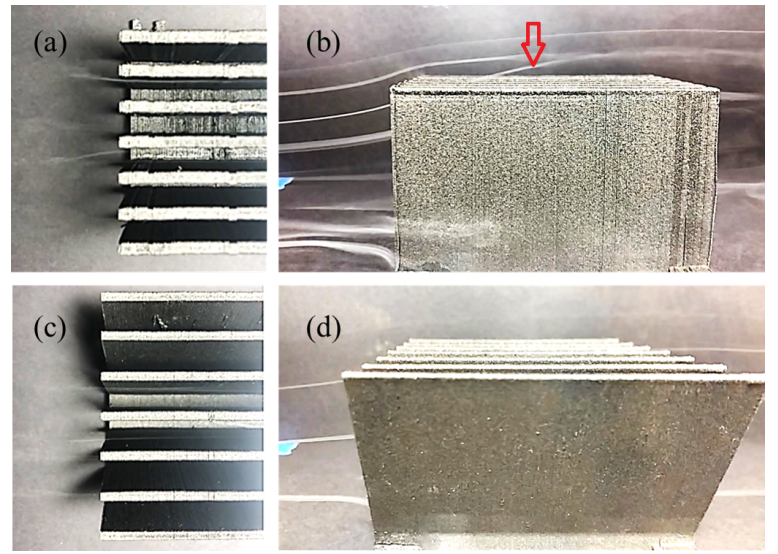

Figure 8. Flow Visualisation for $R e=7.45 \times 10^{4}$ ((a) and (c) shows the top view and (b) and (d) shows the side view of the straight and oblique fins respectively).

\section{Conclusions}

An experimental study has been conducted to investigate the thermal performance of 3D printed heat sinks made of thermal conductive composite polymers (metal filled filaments (copper and bronze) and carbon-based filament (Ice9 Flex)). The straight and oblique finned heat sinks were investigated under force convection over the range of $74200 \sim 360000$, to examine various thermal and flow dynamics characteristics.

The key findings can be listed as follows:

- Oblique fins effectively reduce the thermal resistance of heat sinks in comparison to straight fins.

- Under forced convection, oblique fins provide increased inter-fin velocity with smaller pressure drops.

- Ice9 Flex filament heat sink is much superior in thermal heat dissipation when compared to heat sinks with copper and bronze filled filaments.

\section{References}

[1] U.S. air force avionics integrity program notes.

[2] Al-damook, A. and Alkasmoul, F., Heat transfer and airflow characteristics enhancement of compact plate-pin fins heat sinks - a review, Propulsion and Power Research, 7, 2018, $138-146$.

[3] Cabeza, L. F., Advances in thermal energy storage systems: Methods and applications, Elsevier, 2014.
[4] Chen, Y.-M. and Ting, J.-M., Ultra high thermal conductivity polymer composites, Carbon, 40, 2002, 359-362.

[5] Chingulpitak, S. and Wongwises, S., A review of the effect of flow directions and behaviors on the thermal performance of conventional heat sinks, International Journal of Heat and Mass Transfer, 81, 2015, 10 - 18.

[6] Elghool, A., Basrawi, F., Ibrahim, T. K., Habib, K., Ibrahim, H. and Idris, D. M. N. D., A review on heat sink for thermo-electric power generation: Classifications and parameters affecting performance, Energy Conversion and Management, 134, 2017, 260 - 277.

[7] Garzon-Hernandez, S., Garcia-Gonzalez, D., Jérusalem, A. and Arias, A., Design of fdm 3d printed polymers: An experimental-modelling methodology for the prediction of mechanical properties, Materials Design, 188, 2020, 108414.

[8] Khattak, Z. and Ali, H. M., Air cooled heat sink geometries subjected to forced flow: A critical review, International Journal of Heat and Mass Transfer, 130, 2019, 141 -161 .

[9] Mamunya, Y., Davydenko, V., Pissis, P. and Lebedev, E., Electrical and thermal conductivity of polymers filled with metal powders, European Polymer Journal, 38, 2002, $1887-1897$.

[10] Mohd Pu'ad, N., Abdul Haq, R., Mohd Noh, H., Abdullah, H., Idris, M. and Lee, T., Review on the fabrication of fused deposition modelling (fdm) composite filament for biomedical applications, Materials Today: Proceedings.

[11] Mun, S. Y., Lim, H. M. and Lee, D.-J., Thermal conductivity of a silicon carbide/pitch-based carbon fiber-epoxy composite, Thermochimica Acta, 619, 2015, 16 - 19.

[12] Turner, B. N., Strong, R. and Gold, S. A., A review of melt extrusion additive manufacturing processes: I. process design and modeling, Rapid Prototyping Journal.

[13] Vadivelu, M. A., Kumar, C. R. and Joshi, G. M., Polymer composites for thermal management: a review, Composite Interfaces, 23, 2016, 847-872.

[14] Webbe Kerekes, T., Lim, H., Joe, W. Y. and Yun, G. J., Characterization of process-deformation/damage property relationship of fused deposition modeling (fdm) 3dprinted specimens, Additive Manufacturing, 25, 2019, 532 -544 . 